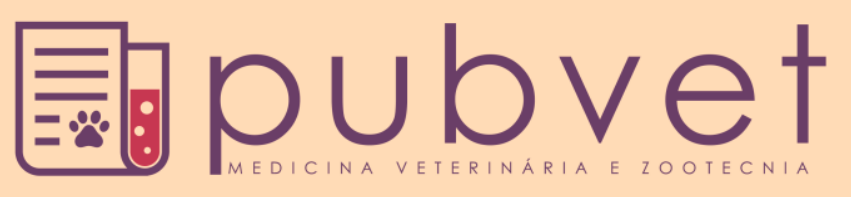

ISSN $1982-1263$

https://doi.org/10.22256/pubvet.v12n2a35.1-11

\title{
Estudo do mercado e produção do cavalo brasileiro de hipismo no estado de São Paulo
}

\author{
Bruna Egydio de Sousa Santos ${ }^{\ominus}$ 1, Roberta Ariboni Brandi ${ }^{\ominus}$, Augusto Hauber Gameiro ${ }^{\ominus} 3 *$ \\ ${ }^{1}$ Mestre em Gestão e Inovação na Indústria Animal pela Universidade de São Paulo, Faculdade de Zootecnia e Engenharia de Alimentos, \\ Pirassununga-SP. E-mail: brunaegydio@usp.br \\ ${ }^{2}$ Professora da Universidade de São Paulo, Faculdade de Zootecnia e Engenharia de Alimentos, Departamento de Zootecnia. Pirassununga-SP. \\ E-mail: robertabrandi@usp.br \\ ${ }^{3}$ Professor da Universidade de São Paulo, Faculdade de Medicina Veterinária e Zootecnia, Laboratório de Análises Socioeconômicas e \\ Ciência Animal, Pirassununga-SP. \\ *Autor para correspondência, E-mail: gameiro@usp.br
}

RESUMO. O Brasil possui aproximadamente 5,8 milhões de equinos. Destes, 8.700 são Brasileiro de Hipismo, registrados na associação que a representa. A indústria do cavalo movimenta, no Brasil, $\mathrm{R} \$ 16,15$ bilhões ao ano e gera 610 mil empregos diretos e indiretos. A raça Brasileira de Hipismo teve exemplares convocados para as equipes brasileiras em competições sul-americanas, pan-americanas e olimpíadas. A crescente demanda por animais da raça e o bom desempenho em competições têm tornado este mercado bastante relevante. Objetivou-se determinar a estrutura o mercado de cavalos da raça Brasileiro de Hipismo no Brasil; obter informações sobre a oferta e a demanda pela raça; determinar os custos médios de produção e manutenção dos cavalos; e propor uma tipologia dos seus usuários. A Associação Brasileira dos Criadores do Cavalo de Hipismo forneceu informações sobre a produção e a comercialização dos animais. Aplicaram-se questionários para o levantamento de dados. Foram entrevistados seis criadores e 25 usuários dos cavalos. Foi utilizada estatística descritiva para análise dos dados. Como resultado, obteve-se que o mercado possui estrutura de concorrência monopolística. Os produtores utilizam a inseminação artificial (50\% dos casos) e a transferência de embrião (33,33\%), buscando o aperfeiçoamento dos animais. O custo médio anual de produção, por animal, foi estimado em $\mathrm{R} \$ 5.709,72$. O custo médio de manutenção de um animal foi de $\mathrm{R} \$ 2.587,80$ mensais. A principal destinação dos animais é o esporte, principalmente para o salto e concurso completo de equitação. Os consumidores fazem parte de classe social elevada. Observouse que o cavalo traz benefícios não financeiros aos criadores e usuários. E concluiu-se que a produção pode não ser considerada eficiente, no que diz respeito à rentabilidade.

Palavras chaves: Concorrência monopolística, demanda, equinocultura, oferta

\section{Study of the market and production of Brasileira de Hipismo Horse breed in the State of São Paulo, Brazil}

ABSTRACT. Brazil has a herd of approximately 5.8 million horses, of which 8,700 belong to the Brasileira de Hipismo breed. The breed has represented Brazil in South American, Pan American and Olympic competitions. The growing demand for these animals and their good performance in competitions has become a quite promising market. Research on it, however, is still scarce. As objectives, the research aimed to determine the structure of the Brasileira de Hipismo market in Brazil; obtain information on the breed supply and demand; estimate average horse production and maintenance costs, and propose users breed typology. The Brazilian Association of Equestrian Horse breeders provided information on animal production and marketing. Questionnaires were used to collect data. 
Six breeders and 25 horse users were interviewed. Descriptive statistics was employed for data analysis. As results, the market is characterized as a monopolistic competition. Breeders use artificial insemination (50\%) and embryo transfer (33\%), searching for high quality horses. The average annual cost of production per animal was estimated at $\mathrm{R} \$$ 5,709.72. The average maintenance cost was $\mathrm{R} \$ 2,587.80$ per animal per month. The animals are mainly used for sports. The study concluded that the horse provides other than financial benefits to breeders and production cannot be considered efficient in terms of profitability. Consumers belong to higher social classes and, for the most part, regard their horses as pets.

Key words: Demand, horse production, monopolistic competition, offer

\section{Estudio del mercado y producción del caballo Brasileño de Hipismo en el estado de São Paulo}

RESUMEN. El Brasil cuenta con un rebaño de aproximadamente 5,8 millones de caballos, de los cuales 8,700 pertenecen a la raza Brasileiro de Hipismo, registrada en su asociación representativa. En su conjunto, el agronegocio brasileño de caballos envuelve un mercado de $\mathrm{R} \$ 16,15$ billones por año y genera 610 mil empleos directos e indirectos. La raza de caballos Brasileiro de Hipismo ha representado a Brasil en competiciones sudamericanas, panamericanas y olímpicas. El Objetivo fue determinar la estructura del mercado de la raza Brasileiro de Hipismo en Brasil; obtener información sobre la oferta y la demanda por la raza; estimar la producción media y los costos de mantenimiento de los caballos y proponer una tipología de los usuario. A Asociación Brasileira de Criadores del Caballo de Hipismo proporcionó información sobre la producción y comercialización de los animales. Se utilizaron cuestionarios para recopilar los datos. Se entrevistaron seis criadores y 25 usuarios de caballos. Estadística descriptiva fue usada para el análisis de los datos. El mercado se caracteriza por una competición monopolística. Los criadores utilizan inseminación artificial (50\%) y transferencia de embriones (33\%). El costo promedio anual de producción por animal fue estimado en $\mathrm{R} \$ 5.709,72$. El costo promedio de mantenimiento fue de $\mathrm{R} \$ 2,587.80$ por animal por mes. Para los criadores, el caballo de la raza Brasileiro de Hipismo ofrece otros beneficios que no son económicos. Los consumidores pertenecen a las clases sociales más altas y en su mayoría, consideran a sus caballos como mascotas.

Palabras claves: Competencia monopolística, demanda, oferta, producción de caballos

\section{Introdução}

O Brasil possui maior rebanho de equinos da América Latina, com 5,8 milhões de cabeças (ANUALPEC, 2017). A indústria equina mobiliza ao ano R $\$ 16$ bilhões (MAPA, 2016). Os equinos da raça do Brasileiro de Hipismo participaram dos Jogos Pan-Americanos (2015) e olimpíadas (2016). Este mercado apresenta grande assimetria de informação (Egbert, 2007). Akerlof (1970) determinou que, em um mercado com assimetria de informações, os custos econômicos da desonestidade dos agentes estimulam a venda de bens de baixa qualidade. Esta justificativa pode ser a base para a manutenção de instituições que reduzem tal assimetria. Koenen \& Aldridge (2002) estudaram a criação de cavalos europeus de esporte, e concluíram que a finalidade das organizações de criação de cavalos era melhorar a habilidade do cavalo em competições e que os criadores estavam preocupados com 0 fornecimento de animais de qualidade. Segundo Koenen et al. (2004), as características consideradas importantes pelos produtores eram a conformação, salto, adestramento, marcha, comportamento e saúde do animal. Oddie et al. (2014) afirmaram que os determinantes do preço do cavalo incluíam raça, cor, idade, altura, temperamento e potencial de uso. Vieira (2011) analisou a criação de cavalos Mangalarga, em Minas Gerais. Esta foi uma pesquisa metodológica que incluiu algumas metas semelhantes; porém se concentrou em uma raça de cavalo distinta, produzida em outro estado brasileiro. A hipótese é que o mercado de cavalos Brasileiro de Hipismo parece se enquadrar na estrutura de concorrência monopolística. O presente estudo teve como objetivo reunir informações iniciais do mercado e 
produção de cavalos Brasileiros de Hipismo registrados no Estado de São Paulo; estimar o custo médio de produção e manutenção de cavalos desta raça; determinar o principal destino desses animais e propor uma tipologia do usuário do cavalo Brasileiro de Hipismo.

\section{Material e Métodos}

O estudo foi aprovado pelo Comitê de Ética em Pesquisa Humana, Escola de Zootecnia e Engenharia de Alimentos, Universidade de São Paulo, CAAE número 48516315.3.0000.5422, protocolo número $083233 / 2015$. Os dados foram coletados entre os meses de julho a outubro de 2015.

\section{Justificativa da região escolhida}

De acordo com o IBGE - Instituto Brasileiro de Geografia e Estatística - a população estimada do estado de São Paulo é de 44.749.699 habitantes, abrangendo uma área de 248.221,996 $\mathrm{km}^{2}$, com densidade demográfica de 166 hab. $/ \mathrm{km}^{2}$ e um total de 645 municípios (IBGE, 2016). O estado concentra o maior número de habitantes do país, bem como grande número de empresas e fazendas de criação de animais e produção agrícola. Além do mais, trata-se do estado que possui os dois maiores criadores de Brasileiro de Hipismo, fatos que justificam a escolha da região de estudo.

\section{Delineamento da pesquisa}

O método descritivo de pesquisa exploratória foi utilizado para a coleta de dados de acordo com a metodologia proposta por Lakatos \& Marconi (2010), o qual possui finalidade de descrever fenômeno ainda pouco estudado, encontrando-se descrições qualitativas e quantitativas, utilizandose da técnica de observação participante e da aplicação de questionários. Tal metodologia é utilizada quando um objeto ainda foi pouco estudado, como é o caso do mercado de cavalos Brasileiros de Hipismo (BH). Ainda de acordo com os autores, um estudo exploratório possui a amostragem flexibilizada.

Foram recolhidas informações perante a Associação Brasileira dos Criadores do Cavalo de Hipismo (ABCCH) e, ao mesmo tempo, realizadas coletas de dados pela aplicação de questionários aos proprietários e/ou criadores de cavalos BH. Os questionários eram mistos, e continham questões de múltipla escolha e abertas. O questionário aplicado aos produtores de cavalos da $\mathrm{BH}$ visava compreender o modelo de negócios da criação de cavalos BH's e serviu para reunir informações sobre a comercialização e criação dos cavalos; determinando os principais destinos dos mesmos; quais as tecnologias eram utilizadas; o custo de produção; e estimativas médias de manutenção mensal por animal. O questionário dirigido aos demandantes visava reunir informações sobre o perfil do usuário do cavalo $\mathrm{BH}$, bem como suas preferências; determinar os principais usos dos cavalos; calcular os custos médios de manutenção; e propor uma tipologia dos usuários de cavalos BH. Para evitar o viés de seleção dos demandantes, foram entrevistados usuários de cavalos de várias raças, incluindo o $\mathrm{BH}$. Os questionários foram aplicados pessoalmente e por meios eletrônicos. Os criadores, entrevistados pessoalmente, eram das cidades de Pirassununga haras que teve dois animais de sua criação selecionados para as olimpíadas de Sidney (2000) e Rio de Janeiro (2016) - Ribeirão Preto e Batatais, no estado de São Paulo.

Algumas fazendas responderam ao questionário por correio eletrônico, como foi o caso dos haras localizados nas cidades de Arandú - um dos maiores do Brasil - Porto Feliz e Ribeirão Preto, também no estado de São Paulo. O número total de criadores entrevistados foi de seis. Os criadores entrevistados eram todos cadastrados na $\mathrm{ABCCH}$. Os demandantes, por sua vez, eram os praticantes de equitação, donos de cavalos ou não (independentemente da raça); e proprietários de cavalos, praticantes de esporte ou lazer. Os demandantes foram entrevistados pessoalmente, em um centro de equitação localizado na cidade de Pirassununga, bem como em uma escola de equitação na cidade de Ribeirão Preto. As duas escolas de equitação eram respectivamente, de dois cavaleiros que fizeram parte de equipes brasileiras em competições como Pan-americanos e Olimpíadas. Vinte e três indivíduos e duas entidades legais (as duas escolas de equitação visitadas) foram entrevistados.

Foi realizada revisão de literatura econômica e de estudos sobre criação de cavalos, o que possibilitou determinação dos fatores que ocasionavam mudanças nas quantidades ofertadas e demandadas do cavalo BH. Tais informações são apresentadas no Quadro 1.

Após a coleta de dados, os mesmos foram tabulados e utilizou-se de estatística descritiva para análise, tais como média aritmética, frequência e percentual. 
Quadro 1. Fatores que ocasionam mudanças nas curvas de demanda e oferta do cavalo Brasileiro de Hipismo.

\begin{tabular}{|ll|}
\hline Demanda & Oferta \\
\hline Preço de outras raças de cavalo & Preço dos insumos (itens utilizados na produção animal) \\
Preço de outras atividades de lazer & Tecnologias utilizadas na produção \\
Renda do consumidor & Expectativas dos ofertantes \\
Gostos, preferências por outras raças & \\
Expectativas dos demandantes & \\
\hline
\end{tabular}

Fonte: adaptado de Varian (2006).

\section{Resultados}

Foram identificados 1.137 produtores registrados na $\mathrm{ABCCH}$, localizados no Estado de São Paulo. A ABCCH informou que o número de animais registrados entre 1995 e 2013 foi de 8.631,00. Tal índice se manteve em ascensão até o ano de 2011, e após esse período começou a cair ano após ano. Da mesma forma que essa pesquisa, Egbert (2007) ao estudar o comércio de cavalos em três mercados distintos, localizados na Alemanha, apontou que houve queda no número de animais oferecidos nestes mercados nas últimas décadas. Isto se justificou, principalmente, porque esses animais anteriormente eram utilizados na agricultura e na indústria, e atualmente são destinados, em sua maioria, a práticas esportivas e lazer. No caso do BH, uma vez que os animais foram destinados à prática do esporte desde que foram criados, a queda que ocorreu desde 2009 pode ser atribuída a um aumento nos custos de produção ou ajustes de mercado.

Entre 2000 e 2013, houve aumento nas transferências de propriedade de animais juntamente à associação da raça. Um dos papéis da Associação era o de ser responsável pelos registros genealógicos dos animais $\mathrm{e}$ a manutenção do stud book da raça. A $\mathrm{ABCCH}$ afirmou que foram tomadas medidas para encorajar o registro da $\mathrm{BH}$ de modo a estimular sua criação. Desta forma, o aumento dos registros entre 1998 e 2009 pode refletir essas ações. A queda nos registros observados a partir do ano de 2010 pode ter sido causada por esse incentivo: houve um boom devido a incentivos $\mathrm{e}$, em seguida, o número de registros normalizados (comunicação pessoal, 06 de julho de 2016).

Em seis leilões realizados pela $\mathrm{ABCCH}$, entre agosto de 2013 e agosto de 2014, o preço médio era de $\mathrm{R} \$ 18.000$ para animais de um ano; $\mathrm{R} \$$ 25.000 para os de dois anos, $\mathrm{R} \$ 30.000$ os cavalos de três anos e R\$ 40.000 os de quatro anos (comunicação pessoal, 26 de agosto de 2014). O aumento do valor dos animais à medida que envelhecem é devido à sua melhora no desempenho atlético, o qual contribui para elevar as expectativas positivas dos agentes, seja dos ofertantes ou dos demandantes.

A fim de melhorar a organização do mercado do cavalo $\mathrm{BH}$, a associação de criadores permite uma melhor gestão da raça, evitando o oportunismo dos agentes, impedindo a perda de linhagem do animal, de maneira que não sejam fornecidos produtos de baixa qualidade, conforme previsto (Akerlof, 1970).

\section{Considerações sobre a demanda do cavalo BH}

Com relação à demanda de cavalo da $\mathrm{BH}$, a distribuição da renda familiar dos indivíduos foi a seguinte: 11 tinham renda superior a $\mathrm{R} \$$ $11.820,00$; três possuíam renda entre $\mathrm{R} \$ 9.456,01$ e R\$11.820,00. Outros três entrevistados tinham familiar entre $R \$ 7.092,01$ e $R \$ 9.456,00$ e um entrevistado apresentava renda entre $\mathrm{R} \$ 788,01 \mathrm{e}$ $\mathrm{R} \$ 2,364,00$. O número total de respostas para esta questão foi de 18. Como referência, utilizou-se a seguinte classificação de renda média mensal, utilizada pela ABEP - Associação Brasileira de Empresas de Pesquisa: Classe A - acima de R \$ 20.272,56; Classe B1 - de R \$ 8.695,88; Classe B2 - R\$ 4.427,36; Classe C1 - R\$ 2.409,01; Classe $\mathrm{C} 2-\mathrm{R} \$ 1.446,24$ e classes D-E - R\$ 639,78. Quanto à renda média de cada entrevistado, sete de um total de 21 entrevistados declararam que não tinham renda própria, o que pode ser explicado pelo fato de tratar-se de estudantes; cinco deles apresentavam renda superior a $\mathrm{R} \$$ 11.820. É razoável dizer que a maioria dos demandantes pertence a uma classe social elevada, o que pode sugerir que o cavalo seja um bem de luxo.

Com relação à profissão dos entrevistados, a maioria era de estudantes, seguidos por veterinários e empresários. Os entrevistados tinham, em sua maior parte, idade inferior a 41 anos. As faixas etárias mais comuns foram as entre 9 a 14 anos e as 21 a 27 anos. A maior idade observada foi de 65 anos. Comparando a este estudo, com outro realizado por Martinson et al. 
(2006) em que foram coletadas informações sobre a indústria do cavalo no estado americano de Minnesota, a idade média dos proprietários foi menor. Em Minnesota, a idade média era de 44 anos.

Com relação ao alojamento dos animais, os cavalos eram acomodados principalmente em hípicas, próximas às residências dos proprietários, observando-se maior distribuição de acomodações de cavalos em centros equestres (18 de 25 respostas), seguidas por fazendas (4 de 25 respostas) e outras (3 respostas).

O elevado número de jovens dentre os entrevistados, revela a prevalência de amadores no esporte ( 20 dos 25 das respostas). Além disso, os amadores procuram atividades equestres no esporte e lazer, o que é justifica a concentração em centros equestres, os quais são bem estruturados, favorecendo a prática do esporte amador. Os profissionais que responderam ao questionário incluíam prestadores de serviços, proprietários de escolas de equitação ou instrutores equestres.

Ao questionar aos entrevistados "o que o cavalo representava para eles", 14 de um total de 41 respostas válidas (esta questão admitia mais de uma resposta), consideravam cavalos como "membros da família". Esse resultado pode refletir o público que participou da pesquisa (praticantes predominantemente amadores). Verificou-se que a maioria dos animais eram utilizado todos os dias, o que pode sinalizar uma atividade de lazer e esporte para os proprietários, bem como um uso intensivo de cavalos em centros de treinamento (equestres).

A maioria dos entrevistados $(57,9 \%)$ estava envolvida em outras atividades esportivas (o número total de respostas para esta questão foi de 19). Entre as outras atividades praticadas pelos usuários de cavalos, as mais frequentes eram musculação, futebol, corrida, natação e ciclismo.

Quando questionado sobre a motivação para realizar o esporte, houve uma prevalência de respostas daqueles que simplesmente gostavam de cavalos (demonstrando que o cavalo assume um papel de animal de estimação), bem como daqueles que o viram como uma atividade boa para o alívio do estresse. Como esses animais são mais frequentemente comprados para uso pessoal, há uma forte tendência de considerá-los como animais de estimação e, como resultado, o custo da atividade se torna menos relevante. Isto foi reforçado pelas respostas dos entrevistados, que declararam que não iriam trocar equitação por qualquer outra atividade esportiva ou de lazer. Dos entrevistados, 12 praticavam concurso completo de equitação $(44,4 \%)$ e 10 o salto $(37,0 \%)$. O adestramento $(11,1 \%)$ e outras modalidades $(7,4 \%)$ também foram observadas. Ao comparar as percentagens de modalidade desportiva dos entrevistados com os dados obtidos por Martinson et al. (2006) que apontaram que 67\% dos proprietários usavam seus animais para esporte, observou-se que a porcentagem de proprietários que praticavam equitação usando a raça do cavalo Brasileiro de Hipismo era maior $(92,5 \%$ dos entrevistados). Como equitação, foram consideradas as modalidades de salto, adestramento e concurso completo de equitação.

Quanto ao número de animais de propriedade dos entrevistados, 13 deles tinham apenas um animal, seguido por seis, que detinham dois animais. Esta questão totalizou 25 respostas. O estudo americano de Martinson et al. (2006) apontou que os proprietários tinham, em média, 14 animais. Tal diferença se deve, principalmente, pela diferença na conjuntura econômica dos dois países.

Por outro lado, ao analisar o número de pessoas que usam o mesmo animal, em 14 casos $(58,3 \%)$ os animais eram usados apenas por uma pessoa, seguidos de sete casos em que os animais eram utilizados por duas pessoas (proprietário e treinador). Esta questão incluiu 24 repostas.

Observou-se que $35 \%$ dos cavalos declarados na pesquisa pertenciam à raça $\mathrm{BH}$. Observou-se um total de 177 animais, de 10 raças diferentes, bem como animais sem raça definida. A distribuição das raças é dada no Tabela 1.

A quantidade elevada de animais sem raça definida pode ser justificada pelas entrevistas terem sido realizadas em duas escolas de equitação, que possuem animais para uso dos alunos. $\mathrm{O}$ fato de o $\mathrm{BH}$ ser o segundo maior em percentagem demonstra a relevância da raça no Estado e reforça o potencial desta raça na área estudada.

Quanto à compra de animais da $\mathrm{BH}$, houve alguns fatores motivadores da mesma, sendo os mais importantes à qualidade (13 de 47 respostas), a saúde, a versatilidade e o resultado em competições (cada uma com 9 de 47 respostas). $\mathrm{O}$ entrevistado poderia escolher mais de uma opção de motivação de compra. As qualidades enfatizadas são um reflexo do propósito do uso 
animal, principalmente para competição (profissional ou amador), condição que valoriza a saúde animal, de modo que a versatilidade e os recursos de qualidade sejam aprimorados. Como pode ser observada em entrevistas, a compra do animal não ocorreu, em sua maior parte, levando em conta os preços mais baixos, mas outros atributos de $\mathrm{BH}$, como qualidade e saúde.

Tabela 1. Distribuição da frequência de animais de posse dos respondentes por raça, e percentual de cada raça declarada

\begin{tabular}{lcc}
\hline Raça & Número Animais Cavalos da raça, $\%$ \\
\hline Sem raça definida & 65 & $37 \%$ \\
Brasileiros de Hipismo & 62 & $35 \%$ \\
Anglo & 31 & $18 \%$ \\
Puro Sangue Inglês & 6 & $3 \%$ \\
Mangalarga & 5 & $3 \%$ \\
Quarto de Milha & 2 & $1 \%$ \\
Lusitano & 2 & $1 \%$ \\
Paint Horse & 1 & $1 \%$ \\
Oldenburgo & 1 & $1 \%$ \\
Sela Argentina & 1 & $1 \%$ \\
Andaluz Brasileiro & 1 & $1 \%$ \\
Total & 177 & $100 \%$ \\
\hline
\end{tabular}

Fonte: Autores.

Em contrapartida, um estudo realizado por Akerlof (1970) do mercado de carros usados, onde havia uma grande possibilidade de o comprador comprar um carro de má qualidade (apelidado de "limão" pelo autor), também pode ser mencionado. Em uma analogia com o mercado de carros usados, existe uma grande chance de o demandante do cavalo BH obter um animal de qualidade inferior ao que ele esperaria ter, uma vez que existe uma assimetria de informação significativa nesse mercado. Em geral, os fornecedores de cavalos têm mais informações sobre o produto que os compradores, os quais correm o risco de obter um "limão".

Ao analisar o valor investido em aulas e treinamento, verificou-se que a maioria dos entrevistados tinha um investimento mensal inferior a $\mathrm{R} \$ 1.000,00$, o que pode refletir o tipo de público que frequenta escolas de equitação, pois o amadorismo era significativo. À medida que a atividade é desenvolvida, são necessários maiores investimentos em treinamento, levando a custos mais elevados (como é o caso de um profissional entrevistado, que pagava $\mathrm{R} \$ 5.000,00$ por mês com aulas e treinamento).
Os valores da estabulação do animal variaram entre $\mathrm{R} \$ 600,00$ a $\mathrm{R} \$ 1.500,00$ mensais. Nos casos em que os valores estavam entre $\mathrm{R} \$ 1.000,00$ e $\mathrm{R} \$$ 1.500,00 (15 em 21 respostas), a alimentação era inclusa no valor da mensalidade das baias. A estrutura dos centros equestres favorece a interação entre participantes esportivos e suas famílias, além de oferecer atividades recreativas, uma vez que competições equestres também podem ocorrer nesses espaços. Além disso, os animais precisam se concentrar no treinamento e as instalações equestres fornecem o ambiente ideal para que esses animais permaneçam focados na atividade. Devido às instalações disponíveis nos centros equestres, a maioria dos animais está alojada neles.

O custo mensal médio estimado de manutenção por animal foi de $\mathrm{R} \$ 2.587,80$, o qual não inclui os custos com veterinário, medicamentos ou transporte, nem registro nas agências responsáveis pela organização de competições e exames. Esses custos podem variar substancialmente de acordo com o nível de competição ao qual o animal esteja sujeito, bem como a modalidade praticada.

Em 87,5\% dos casos, o animal era destinado ao uso pessoal, o total de respostas foi de 24. Das pessoas que compraram os animais para fins comerciais, metade esperava que os mesmos tivessem valorização de $50 \%$ e a outra metade esperava que seus animais dobrassem de valor. Portanto, prevaleceu uma expectativa positiva em relação ao mercado, por parte dos demandantes dos animais. Uma característica interessante do mercado de cavalos é o fato de que, seus preços de revenda seja maiores do que os preços iniciais. Isso se deve ao desenvolvimento e ao treinamento ao qual o animal é submetido. Essa diferença entre preços iniciais e futuros pode levar à necessidade de arbitragem (como no caso da compra do animal para fins de investimento).

\section{Considerações sobre a oferta do cavalo $B H$}

Com relação aos aspectos relacionados à produção do cavalo Brasileiro de Hipismo, um dos destaques refere-se às biotecnologias utilizadas na reprodução. Prevaleceu o uso de inseminação artificial (IA) - 6 de um total de 12 respostas (50\%). IA é uma técnica contemporânea que é amplamente aceita pela associação da raça $\mathrm{BH}$; seguiu-se a transferência de embriões (TE) - 4 de um total de 12 respostas $(33,3 \%)$ - uma técnica mais moderna e que agrega valor ao produto, também é admitida pela $\mathrm{ABCCH}$. Esta questão 
poderia ter mais de uma opção de biotecnologia como resposta. Com referência aos aspectos tecnológicos, o uso da biotecnologia reprodutora sugere maior comprometimento dos criadores com o melhoramento genético animal. Isto permite a oferta de animais de qualidade, com o consequente aumento do preço no mercado, atingindo, em algumas ocasiões, uma diferenciação que fornece o poder de monopólio do proprietário, como mencionado anteriormente. Ao comparar esses resultados com os obtidos por Vieira (2011) que estudou a criação do cavalo Mangalarga no Estado de Minas Gerais, observouse que as taxas de uso de IA (50\% para $\mathrm{BH}$ em oposição a 13,1\% para Mangalarga) e TE (33,3\% para $\mathrm{BH} \times 15,9 \%$ para Mangalarga) foram maiores. Além disso, ao comparar os dados obtidos por Ray \& Grimes (1991) concluiu-se que a realidade dos criadores de cavalos americanos e dos criadores de cavalos Brasileiro de Hipismo é bastante semelhante às técnicas de reprodução. A inseminação artificial é frequentemente usada em ambos os países, de modo a buscar o melhoramento genético animal, oferecendo qualidade e animais diferenciados no mercado. Tanto no caso de raças de cavalos americanos quanto do $\mathrm{BH}$, as associações foram estabelecidas por donos de fazendeiros, com a finalidade de supervisionar e fortalecer a criação. Ray \& Grimes (1991) afirmam ainda que as associações de criadores eram responsáveis pela monitoração do stud book. $\mathrm{O}$ mesmo ocorre na $\mathrm{ABCCH}$, que é responsável pela regulação e promoção da raça BH no Brasil, cumprindo o papel identificado pelos autores norte-americanos, tentando manter a pureza e a qualidade dos cavalos criados com a ajuda do stud-book.

Koenen \& Aldridge (2002) apontaram que o objetivo dos produtores de uma raça diferentes raças europeias de cavalo de esporte, os warmbloods era buscar o melhor desempenho dos animais nas três principais modalidades do hipismo (salto, adestramento e concurso completo de equitação). Em razão da melhora genética dos animais, empregando tecnologias de reprodução, com uso de sêmen de garanhões e óvulos de éguas de renome mundial. Este também foi o caso da criação de cavalo BH. Esta alta taxa de IA e TE mostra a preocupação dos criadores em promover a melhoria genética animal, favorecendo seu desempenho nos esportes a que estão destinados, como observado nos resultados obtidos por este estudo. Verificou-se que nem todos os animais disponíveis eram utilizados na reprodução, o que pode sugerir que há um monitoramento do mercado por parte dos ofertantes para disponibilizar um número específico de animais por ano, mantendo o valor genético na fazenda. $\mathrm{O}$ tamanho do plantel dos entrevistados variou de 12 a 180 , todos da raça $\mathrm{BH}$. A fazenda com o maior número de BH's também incluiu 60 cavalos andaluzes brasileiros. Dos haras que usavam seus próprios garanhões na reprodução, um deles tinha um animal para cada três éguas usadas na reprodução e outro usava um garanhão para seis éguas; uma terceira fazenda não relatou a proporção de éguas/ garanhão, sugerindo que esses animais eram usados apenas para monta natural, quando o uso de IA e TE não se tornava possível. Metade das fazendas não tinha garanhão, usando sêmen congelado ou fresco na reprodução. As fazendas que possuíam garanhões (três criadores) foram questionadas sobre quais atividades os mesmos eram empregados. Cinco respostas foram obtidas, e algumas fazendas usavam tais animais em mais de uma atividade. As atividades relatadas foram a reprodução (dentro da propriedade), que incluiu 2 das 5 respostas; venda de sêmen, 1 de 5 e competições, 2 de 5 respostas. No estudo de Martinson et al. (2006), 49\% dos entrevistados obtiveram parte de sua renda com a venda de cavalos, $46 \%$ da taxa de reprodução, $32 \%$ de equitação e transporte e $16 \%$ de vendas de feno. Ao comparar essa informação com a do mercado de cavalos Brasileiro de Hipismo, os produtores entrevistados utilizaram seus animais para reprodução dentro da porteira em $40 \%$ dos casos.

Os custos de dose de inseminação artificial (IA) e custos de mão de obra associados tiveram uma influência significativa no método de reprodução utilizado, o que levou a uma heterogeneidade de dados. Estes custos são apresentados na Tabela 2.

Tabela 2. Custos da dose e do trabalho da Inseminação artificial

\begin{tabular}{lcc}
\hline Criador & Custo da dose, $\mathrm{R} \$$ & Custo do trabalho, $\mathrm{R} \$$ \\
\hline 1 & 2.130 a 12.780 & Não informado \\
2 & 2.000 & 2.000 \\
3 & Não informado* & 2.000 \\
$4 * *$ & $1.500^{* * *}$ & $2.000^{* * *}$ \\
5 & Não informado & 3.000 \\
$4 * *$ & $5.000^{* * * *}$ & $3.500^{* * * *}$ \\
6 & 4.260 a 8.520 & 6.000
\end{tabular}

*Sêmen próprio, **Sêmen fresco e congelado do criador, ***Sêmen fresco, ****Sêmen congelado. Fonte: Própria autoria. 
$\mathrm{O}$ custo mais alto para uma dose de sêmen foi de $\mathrm{R} \$ 12.780,00$ e o menor foi de $\mathrm{R} \$ 1.500,00$. Quanto aos custos associados ao trabalho de IA, incluindo o serviço necessário para a inseminação, o valor mais alto foi de $\mathrm{R} \$ 6.000,00$ e o menor, $\mathrm{R} \$$ $2.000,00$. Os custos de dose mais elevados referem-se a doses importadas de sêmen, principalmente da Europa. As fazendas alugaram as éguas receptoras, cujo preço era em média de $\mathrm{R} \$ 1.500,00$. Este custo informado pelos criadores referiu-se a um período médio de 15 meses. Duas fazendas pagaram $\mathrm{R} \$ 3.000,00$ para realizar TE. O custo mais alto por TE observado foi de R\$ $5.000,00$ e o menor foi de $\mathrm{R} \$ 1.500,00$. Vieira (2011) verificou que os custos de IA variavam entre $R$ \$ 185,00 e R \$ 510,00 naquele ano. Os custos de TE na criação de Mangalarga variaram entre $R \$ 1.300,00$ e $R \$ 3.000,00$. O custo mais alto da criação de cavalo $\mathrm{BH}$ provavelmente pode ser explicado pelo efeito da inflação (a pesquisa de Vieira foi em 2011, enquanto este estudo, em 2015). Além disso, ao considerar o destino dos animais (competições), é possível que esse serviço seja mais valorizado devido à importância do melhoramento genético animal, como é o caso da raça Brasileiro de Hipismo.

O preço médio para cada grupo de idade do animal foi de $\mathrm{R} \$ 29.000,00$ para 6 meses, $\mathrm{R} \$$ $18.000,00$ para 12 meses, $\mathrm{R} \$ 42.500,00$ para 24 48 meses e $\mathrm{R} \$ 53.333,00$ para animais de 48 meses. Para animais de 6 meses de idade, o preço mais alto foi de $\mathrm{R} \$ 28.000,00$. Para os animais dentro do intervalo de 24-48 meses, o valor mais alto foi de $\mathrm{R} \$ 60.000,00$, e para os animais com idade superior a 48 meses, o maior valor alcançado foi de $\mathrm{R} \$ 80.000,00$. Se os preços dos animais vendidos dentro da porteira ou em leilões realizados pelos criadores forem comparados com os preços dos animais vendidos em leilões realizados pela $\mathrm{ABCCH}$, os preços dos criadores foram maiores, com exceção de animais de 12 meses de idade, cujo preço médio era praticamente o mesmo.

Considerando-se a realização de leilões, Muto (1983) analisou o mercado de cavalos BöhmBawerk, localizado na Áustria e concluiu que toda compra levava a um ótimo de Pareto. Nesta circunstância, a situação de um dos agentes não melhoraria, sem necessariamente deteriorar a do outro agente. Em uma situação de alocação de recursos ótima de Pareto, ocorre a maximização do lucro do comércio potencialmente disponível no mercado estudado. Nas transações de compra realizadas em leilões, ocorre uma situação próxima do ótimo Pareto, uma vez que as partes concordam com o preço pago pelo animal, e a situação não pode melhorar para um dos dois agentes, sem necessariamente agravar a alocação do outro agente.

Além do mais, conforme afirmado por Oddie et al. (2014) existem vários elementos que determinam o preço de um bem, inclusive o de um cavalo. Quando este é o caso, os elementos são tais como raça, cor, idade, altura, temperamento e potencial usabilidade. Os autores apontaram que animais de diferentes idades e potenciais de uso (qualidade animal), têm preços diferentes. Isso explica por que os animais incluídos neste estudo apresentaram preços distintos, de acordo com a idade e haras criador (os ativos são diferenciados em sua qualidade, portanto, seus preços podem variar de um criador para outro).

Tais informações sugerem que o mercado dos cavalos do Brasileiro de Hipismo tem uma estrutura de competição monopolista, devido à diferenciação de animais provenientes de diferentes fazendas, e também porque os criadores possuem certo monopólio, embora existam muitos deles. A qualidade animal foi o item mais mencionado por demandantes dos cavalos. Da mesma forma, Ray (1990) concluiu que o mercado americano de cavalos também era estruturado como uma competição monopolística.

O número de trabalhadores empregados variou entre 3 e 7, com uma média de 5,4 trabalhadores por fazenda. $\mathrm{O}$ cargo mais comum nas fazendas foi a de tratador (21 funcionários de 39 funcionários declarados). Em seguida, funcionário do campo (sete funcionários), seguidos por cavaleiros (5 pessoas). Os inscritos como "trabalhadores de campo" foram contratados por um único criador, que tinha 7 trabalhadores empregados na criação de cavalos BH. Vieira (2011) apontou que o número médio de funcionários na criação de cavalos Mangalarga era de 3,13 por fazenda. O maior número de funcionários nas fazendas de $\mathrm{BH}$ é reflexo do destino desses animais: como são utilizados para o esporte, a criação destes animais requer cuidados especiais. O fato de os custos mais altos de funcionários serem de veterinários e cavaleiros, pode ser explicado pela importância da manutenção dos animais em competições, para que tenham maior visibilidade e credibilidade no mercado. $\mathrm{O}$ custo mensal médio do tratador foi de $\mathrm{R} \$ 2.000,00$ e o custo mensal médio do cavaleiro, $\mathrm{R} \$ 3.500,00$. O custo mensal mais alto foi de $\mathrm{R} \$$ 
5.000.00 (cavaleiro e veterinário). O menor custo mensal declarado foi o de um trabalhador de serviço geral. Também foi questionado se o fazendeiro era atendido por um veterinário, agrônomo ou zootecnista. Constatou-se que todos os criadores tinham algum tipo de assistência (por um veterinário e/ou agrônomo). Porém nenhum dos criados entrevistados informou ter sido assistido por um zootecnista. As despesas mensais médias com veterinários foram de $\mathrm{R} \$ 2.175,00$ sendo o valor mais alto de $\mathrm{R} \$ 5.000,00$ e o menor, $\mathrm{R} \$ 200,00$. Os custos de agronomia não foram relatados.

Quatro criadores compravam forragem, que consistia em tifton ou coast-cross. Quanto ao concentrado, cinco criadores utilizavam alimentos comerciais. As marcas utilizadas eram Pavo ${ }^{\circledR}$, Socil $^{\circledR}$ e Guabi ${ }^{\circledR}$. Apenas um dos criadores fabricava o concentrado. Esta fazenda usava o milho rolão, farelo de soja, farelo de trigo, feno moído, Coequiplus ${ }^{\circledR}$ e calcita como ingredientes concentrados. O custo médio do concentrado por quilo foi de $\mathrm{R} \$ 1,63$, sendo o menor valor de $\mathrm{R} \$$ 0,90 (para o concentrado preparado na fazenda). $\mathrm{O}$ custo médio do feno foi de $\mathrm{R} \$ 0,67 / \mathrm{kg}$ e o menor, $\mathrm{R} \$ 0,30 / \mathrm{kg}$ (feno produzido na fazenda). Os custos mais baixos apresentados, tanto para concentrado, quanto para alimentação volumosa, eram do maior criador entrevistado.

O estudo de Vieira (2011) de cavalos Mangalarga apontou que 50,5\% dessas fazendas não forneciam concentrado para seus animais, oferecendo somente pastagens, sendo $19,19 \%$ de feno comprado. No caso do BH, todos os criadores forneciam volumoso e concentrado aos animais produzidos. Esta diferença na base alimentar animal entre estas duas raças de cavalo é um reflexo da preocupação do criador do $\mathrm{BH}$ em produzir um animal de alta qualidade, um atleta de alto desempenho, por conta do destino do BH ser o das competições de salto e concurso completo de equitação.

Dois criadores relataram custos de produção em R \$ / mês / animal. Os seus custos médios de produção foram de $\mathrm{R} \$ 970,00$ e os mais baixos, $\mathrm{R} \$$ 500,00 . Para as fazendas que abrigavam animais (aluguel de baias), o valor cobrado pelo serviço variou de R\$ 300 a $\mathrm{R} \$ 1.700,00$. Dos seis criadores entrevistados, três deles ofereciam serviços de acomodação. Estes serviços eram mais utilizados em caso de férias de um animal (entre as temporadas de competição ou por razões de saúde) e na aposentadoria. $\mathrm{O}$ menor custo declarado não incluía a alimentação do animal, e o valor de $\mathrm{R} \$ 1.700,00$ abrangia alimentação e vermífugos. Os custos mensais de medicamentos foram mencionados por dois criadores que oferecem serviços de alojamento. A terceira fazenda que oferecia esse serviço não relatou custos. Os custos médios eram de $\mathrm{R} \$$ $20,00 /$ cavalo/mês e outro de $\mathrm{R} \$ 32,00 /$ cavalo/mês. $\mathrm{O}$ uso de drogas variava de acordo com a necessidade, como em caso de emergência ou algum animal com necessidade especial, como quando uma patologia é diagnosticada.

Foi perguntado se a fazenda tinha cavaleiro. Quatro dos seis criadores entrevistados haviam contratado tais profissionais $(66,7 \%)$. O custo mensal por indivíduo variou entre $\mathrm{R} \$ 2.000,00 \mathrm{e}$ $\mathrm{R} \$ 5.000,00$. Uma propriedade não informou $\mathrm{o}$ custo mensal deste profissional. O número de cavaleiros por fazenda estava diretamente ligado ao tamanho do plantel. Pequenos criadores possuíam apenas um profissional. $\mathrm{O}$ maior criador, por sua vez, o qual tinha 180 animais na fazenda, possuía três cavaleiros como parte da equipe de trabalho. Ao adicionar os custos médios obtidos usando os questionários, obteve-se um custo anual médio de produção/ manutenção de $\mathrm{R} \$ 5.709,72$ por animal.

Quanto à categoria alvo de animais criados nas fazendas, 6 de cada 10 das respostas obtidas relataram que a fazenda alocou seus animais para o salto (60\%). O adestramento e o concurso completo de equitação tiveram duas respostas cada ( $20 \%$ cada modalidade). Alguns criadores apontaram mais de uma categoria alvo. Três fazendas mantinham animais ativos em competições. Foi questionado se os animais tinham sido registrados no $\mathrm{ABCCH}$, e todos os criadores entrevistados responderam que a totalidade dos animais nascidos em suas fazendas havia sido registrada na associação de raça do cavalo Brasileiro de Hipismo.

Cinco dos seis criadores tinham outra fonte de renda. Outras informações relevantes foram que os criadores eram frequentemente os próprios usuários de cavalos. O fato de a maioria dos criadores possuir outra fonte de renda condiz com o estudo de Koenen et al. (2004) que asseverou que a produção do cavalo de esporte europeu podia ser questionada, no que dizia respeito à eficiência econômica. É importante enfatizar que o único haras que afirmou que não havia outra fonte de renda, possuía também a escola de equitação, situada no haras, com cerca de 250 
alunos. Portanto, sua renda não dependia exclusivamente da criação de cavalos.

Os dados obtidos sobre os custos de produção de BH sugerem que esta não é uma atividade lucrativa, embora os criadores não pareçam considerar tal fato relevante. $\mathrm{Na}$ maioria das entrevistas realizadas, ficou claro que os criadores produziam os cavalos porque gostava de equinos, o que sugere que a criação de cavalos parece fornecer benefícios não monetários, como certa satisfação pessoal.

No que diz respeito às expectativas dos produtores, verificou-se que os criadores esperavam alcançar uma maior competitividade no mercado do cavalo de esporte através da busca de melhorar a qualidade dos animais oferecidos pelo uso das biotecnologias de reprodução.

O estudo respondeu aos objetivos iniciais, levantou informação de mercado ainda pouco estudado.

\section{Conclusões}

Os cavalos Brasileiros de Hipismo foram bemsucedidos em competições nacionais e internacionais, incluindo seleções para a equipe equestre brasileira, principalmente no salto e concurso completo de equitação e participaram dos Jogos Pan-americanos de Toronto (2015) e olímpicos de Sidney (2000) e do Rio de Janeiro (2016). Embora tenha havido uma queda no número de animais criados anualmente, o mercado de cavalos Brasileiro de Hipismo mostrou-se promissor, e sua estrutura parece se estruturar como concorrência monopolística. $\mathrm{O}$ seu consumidor é de classe social elevada. O cavalo de esporte faz parte de um nicho no mercado, e sua criação é caracterizada como uma atividade de alto risco, por conta das incertezas do mercado e assimetria de informação. Além do mais, o animal parece trazer benefícios aos criadores e demandantes, os quais não são mensurados monetariamente.

\section{Referências Bibliográficas}

Akerlof, G. A. 1970. The market for" lemons": Quality uncertainty and the market mechanism. The Quarterly Journal of Economics, 84, 8488-8500.

ANUALPEC. 2017. Anuário da Pecuária Brasileira, 20th edn. Instituto FNP, São Paulo, SP, Brasil.
Egbert, H. 2007. The culture of a market: A case study of open-air horse markets. Journal of Institutional and Theoretical Economics, 163, 493-502.

IBGE - Instituto Brasileiro de Geografia E Estatística. 2016. Disponível em: <http://www.ibge.gov.br/estadosat/perfil.php? sigla=sp>. Acesso em: 05 set. 2016.

Koenen, E. P. C. \& Aldridge, L. I. 2002. Testing and genetic evaluation of sport horses in an international perspective. 7th World Congress Applied to Livestock Production. Montpellier, France.

Koenen, E. P. C., Aldridge, L. I. \& Philipsson, J. 2004. An overview of breeding objectives for warmblood sport horses. Livestock Production Science, 88, 77-84.

Lakatos, E. M. \& Marconi, M. A. 2010. Fundamentos da metodologia científica. Fundamentos da metodologia científica. Altas, São Paulo, Brasil.

MAPA. Ministério da Agricultura, Pecuária e Abastecimento. 2016. Revisão do Estudo do Complexo do Agronegócio Cavalo. Disponível em:

http://www.agricultura.gov.br/assuntos/camar as-setoriais-tematicas/documentos/camarassetoriais/equideocultura/anos-

anteriores/revisao-do-estudo-do-complexo-doagronegocio-do-cavalo/view>. Acesso em: 20 set. 2017.

Martinson, K., Hathaway, M., Wilson, J., Gilkerson, B., Peterson, P. \& Del Vecchio, R. 2006. University of Minnesota horse owner survey: Building an equine extension program. Journal of Extension, 44, 1-8.

Muto, S. 1983. Sequential auctions on BöhmBawerk's horse market. Mathematical Social Sciences, 4, 117-130.

Oddie, C. F., Hawson, L. A., McLean, A. N. \& McGreevy, P. D. 2014. Do vendors value safety in the Australian recreational (nonthoroughbred) riding horse market? Journal of Veterinary Behavior: Clinical Applications and Research, 9, 375-381.

Ray, M. A. 1990. Technological change, production efficiency, and regulation in the equine industry. Department of Economics. University of Tennessee, Tennessee, USA.

Ray, M. A. \& Grimes, P. W. 1991. The determinants of breeding regulation in the 
horse industry: an empirical analysis. The Journal of Socio-Economics, 20, 169-180.

Varian, H. R. 2006. Microeconomia, princípios básicos. $7^{\mathrm{a}}$ ed. Elsevier, Rio de Janeiro, Brasil.

Vieira, E. R. 2011. Aspectos econômicos e sociais do complexo agronegócio cavalo no estado de Minas Gerais. Minas Gerais.
Article History:

Received 31 October 2017

Accepted 21 November 2017

Available online 22 January 2018

License information: This is an open-access article distributed under the terms of the Creative Commons Attribution License 4.0, which permits unrestricted use, distribution, and reproduction in any medium, provided the original work is properly cited. 